JOURNAL OF APPLIED SMART ELECTRICAL
NETWORK AND SYSTEMS (JASENS)
ISAS

\title{
Rancang Bangun Smart Home Berbasis Internet of Things
}

\author{
Reski Damayanti ${ }^{1}$, Asriyadi $^{2}$, Mardawia Mabe Parenreng ${ }^{3}$ \\ ${ }^{1}$ Teknik Multimedia dan Jaringan, Teknik Elektro, Politeknik Negeri Ujung Pandang \\ 2Teknik Multimedia dan Jaringan, Teknik Elektro, Politeknik Negeri Ujung Pandang \\ ${ }^{3}$ Teknik Multimedia dan Jaringan, Teknik Elektro, Politeknik Negeri Ujung Pandang \\ 1dreski210@gmail.com*,2asriyadi@poliupg.ac.id, 3mmparenreng@poliupg.ac.id
}

\begin{abstract}
Technological developments continue to develop rapidly until the generation of the Internet of things (IoT). IoT is a collection of objects, in the form of physical devices (hardware / embedded systems) that can exchange information between operators or other devices connected to the system. One of the benefits that can be felt is a smart home or smart home, which is a term used to describe a modern residence, with remote control such as controlling electronic goods. This control is intended for savings in electricity use. By using the ESP32 which functions as a liaison between the device and the internet network so that electronic goods that are available from home can be controlled by using an application installed on the smartphone. Based on tests carried out for the same network with a distance of 20 meters the device is successfully controlled, namely turning on and off the electronic device with a response time of $5 \mathrm{~s}$ for the fastest time and $40 \mathrm{~s}$ for the longest time, then for different networks, the control can still be done. So that with this smart home application, electricity costs can be saved.
\end{abstract}

Keywords : ESP32, Smart Home, Internet of Things, Control

\begin{abstract}
Abstrak
Perkembangan teknologi terus berkembang pesat hingga sampai pada generasi Internet of things (IoT). IoT merupakan kumpulan benda-benda, berupa perangkat fisik (hardware /embedded system) yang mampu bertukar informasi antara operator ataupun perangkat lainnya yang terhubung kedalam sistem. Salah satu manfaat yang saat bisa dirasakan yaitu smarthome atau rumah pintar adalah sebuah istilah yang digunakan untuk menyebut sebuah hunian yang modern, dengan pengontrolan dilakukan dari jarak jauh misalnya pengontrolan pada barang elektronik. pengontrolan ini dimaksudkan untuk penghematan dalam penggunaan listrik. Dengan menggunakan ESP32 yang berfungsi sebagai penghubung antara perangkat dengan jaringan internet sehingga barang elektronik yang ada drumah dapat dikontrol dengan menggunakan aplikasi yang terinstall dismartphone. Berdasarkan pengujian yang dilakukan untuk jaringan yang sama dengan jarak 20 meter perangkat berhasil dikontrol yaitu menyalakan dan mematikan perangkat elektronik dengan waktu merespon sebesar $5 \mathrm{~s}$ untuk waktu tercepat dan 40s untuk waktu terlama, kemudian untuk jaringan berbeda pengontrolan masih dapat dilakukan. Sehingga dengan aplikasi smarthome ini biaya listrik dapat dihemat.
\end{abstract}

Kata Kunci : ESP32, SmartHome, Intenet of Things, kontrol

Diterima Redaksi : 12-12-2020 | Selesai Revisi : 29-12-2020 | Diterbitkan Online : 31-12-2020

\section{Pendahuluan}

Di era globalisasi seperti saat ini ilmu teknologi informasi selalu berkembang dan semakin maju [1]. Perkembangan sistem smarthome merupakan salah satu Hingga mendorong manusia untuk terus berpikir kreatif, aplikasi otomatis yang dapat dimanfaatkan dalam tidak hanya menggali penemuan-penemuan baru, tapi kehidupan sehari-hari [4]. Smarthome atau rumah pintar juga memaksimalkan kinerja sistem dan teknologi yang adalah sebuah istilah yang digunakan untuk menyebut telah ada sebelumnya [2]. Salah satunya perkembangan sebuah hunian yang modern dimana terdapat proses teknologi bidang elektronik yang saat ini sudah sampai proses otomatis didalam sistem rumah tersebut seperti pada generasi Internet of Things (IoT). Internet of salah satunya pada sistem pencahayaan rumah tersebut Things (IoT) merupakan kumpulan benda-benda, berupa [5]. Tujuan dari diciptakannya teknologi ini yaitu untuk perangkat fisik (hardware /embedded system) yang mempermudah penghematan daya energi, meningkatkan mampu bertukar informasi antar operator layanan keamanan, mendapatkan kenyamanan, dan lain ataupun perangkat lainnya yang terhubung kedalam sebagainya [6]. 
Tingginya penggunaan daya listrik karena penggunaan barang elektronik membuat sebagai masyarakat mengeluh khusus bagi sebagian orang yang aktif bekerja di luar rumah. Terkadang karena kesibukan beberapa perangkat elektronik seperti lampu dan AC lupa dimatikan sehingga terkadang menyala sepanjang hari walaupun rumah dalam keadaan kosong. Hal ini tentunya meyebabkan daya listrik naik dan biaya listrik bulanan juga meningkat oleh karena itu dibutuhkan teknologi yang dapat mengontrol penggunaan perangkat elektronik walaupun berada diluar rumah

Dalam penelitian ini akan dibuat sebuah maket yang berfungsi sebagai instalasi listrik. Dari maket ini akan di pasangkan relay dan ESP32 sebagai penghubung antara jaringan internet dengan aplikasi yang telah terintall di smartphone. Sehingga perangkat dapat di kontrol dari jauh dapat dimatikan ataupun dinyalakan dengan menggunakan aplikasi.

\section{Metode Penelitian}

Dalam penelitian ini menggunakan arduino IDE, modul wifi dan bluetooth ESP32. Secara rinci dapat dilihat pada gambar 1. Market terhubung dengan internet melalui beberapa perangkat seperti modul relay dan ESP32. Perangkat tersebut ditanamkan sebuah program yang
mampu mengontrol dan memberikan informasi tentang perangkat elektronik. Bahasa yang digunakan yaitu arduino programing. Informasi dalam bentuk data akan dikirimkan dan dikumpulkan di internet yang kemudian dikirimkan ke perangkat atau smartphone. Firebase berfungsi sebagai cloud server yang bertugas untuk mengumpulkan data atau database. Dan pada sisi input digunakan smart phone yang terdapat aplikasi yang berfungsi untuk mengontrol atau mengirimkan perintah ke device melalui firebase atau cloud server.

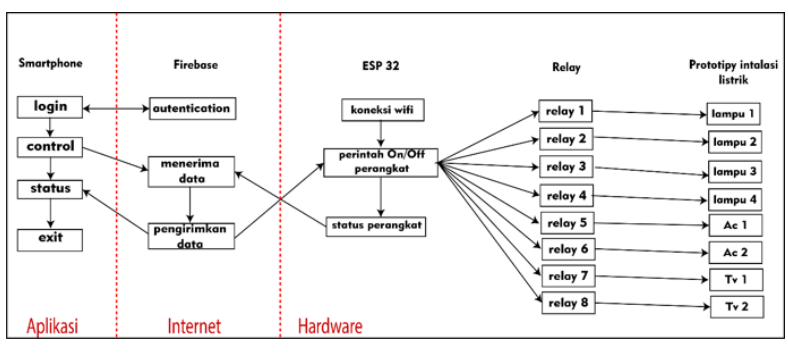

Gambar 1 Blog Diagram Sistem

\subsection{Sketsa Desain Maket}

Sketsa model market yang akan dibuat pada penelitian ini diperlihatkan pada gambar 2. Terdapat 4 buah stop kotak dan 4 buah lampu yang terhubung ke rangkaian relay. Relay tersebut terhubung dengan mikrokontroler yaitu ESP32 yang bertugas untuk mengontrol aktif tidaknya perangkat tersebut.

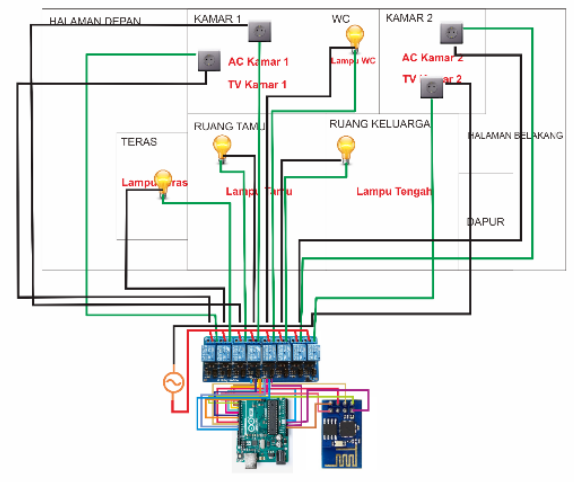

Gambar 2. Sketsa desain maket

Pada sketsa maket ini akan digunakan untuk melakukan uji coba dengan beban AC, dimana pada maket ini menggunakan beberapa lampu dan stop kontak yang di hubungkan dengan relay. Relay akan terhubung dengan ESP32 yang berisi sebuah program untuk mematikan dan menghidupkan lampu dan stop kontak dengan bantuan smartphone dengan sebuah aplikasi.

\subsection{Flowchart Menjalankan Program}

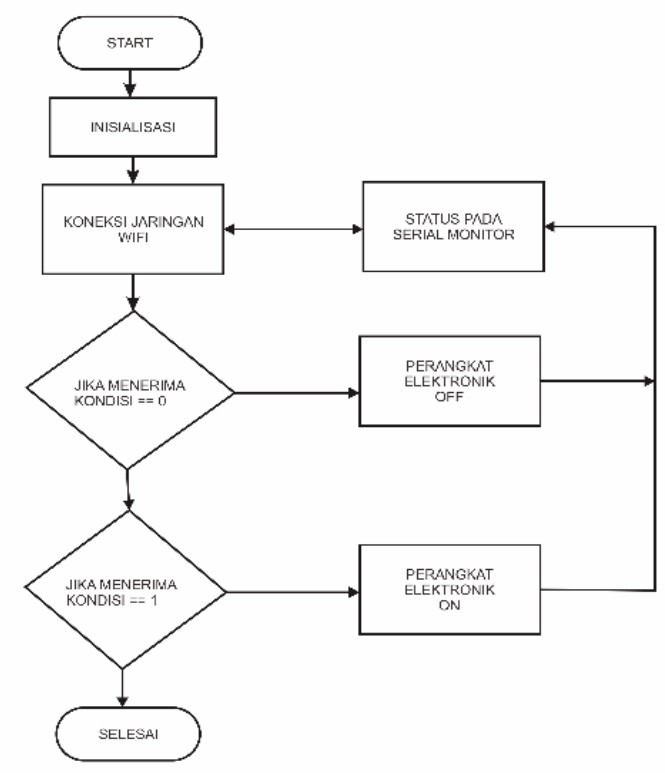

Gambar 3. Flowchart menjalankan program

Pada gambar 3 merupakan jalannya program pada arduino IDE, dimana pada awal program akan melakukan setting jaringan wifi untuk terhubung dengan esp32. Selanjutnya mendefinisikan setiap perangkat, dimana ketika perangkat bernilai 0 maka perangkat akan mati sebaliknya ketikan berangkat bernilai 1 maka perangkat akan hidup. Dan setiap perangkat akan menampilkan status di serial monitor. 


\subsection{Skenario Pengujian}

Skenario pengujian adalah pengujian atau pengetesan antara aplikasi dengan perangkat keras. Setiap unik pada pengkat lunak (aplikasi) dan perangkat keras (hardware) diuji agar dapat diperiksa apakah aliran masukan (input) dan keluaran (output) dari setiap unik sudah sesuai dengan yang diinginkan. Pengujian ini akan dibagi menjadi tiga bagian antara lain:

\section{a. Pengujian dengan jaringan yang sama}

Pada pengujian ini aplikasi akan menggunakan jaringan yang terkoneksi dengan perangkat keras (hardware) untuk melakukan pengontrolan. Dalam pengujian ini digunakan untuk mengetahui apakah aplikasi berfungsi sesuai yang semestinya terhadap hardware, bukan hanya itu pengujian ini juga digunakan untuk mengetahui seberapa jauh jarak aplikasi dalam melakukan pengontrolan.

\section{b. Pengujian dengan jaringan yang berbeda}

Pada pengujian ini aplikasi akan menggunakan jaringan yang berbeda dengan yang digunakan pada perangka keras (hardware). Dalam pengujian ini digunakan untuk mengetahui apakah aplikasi berfungsi sesuai yang semestinya dalam pengontrolan, bukan hanya itu pengujian ini akan dilakukan dibeberapa tempat yang berbeda untuk mengetahui sejauh mana aplikasi ini dapat melakukan pengontrolan terhadap hardware.

\section{c. Pengujian untuk mengetahui waktu tunda}

Dalam pengujian ini digunakan untuk mengetahui waktu yang dibutuhkan hardware untuk bisa berjalan setelah aplikasi dijalankan. Pengujian ini juga akan membandingkan apakah ada perbedaan waktu ketika aplikasi menggunakan jaringan yang sama dengan aplikasi menggunakan jaringan yang berbeda.

\section{Hasil dan Pembahasan}

\section{1 hasil rancangan Mit App Invnetor}

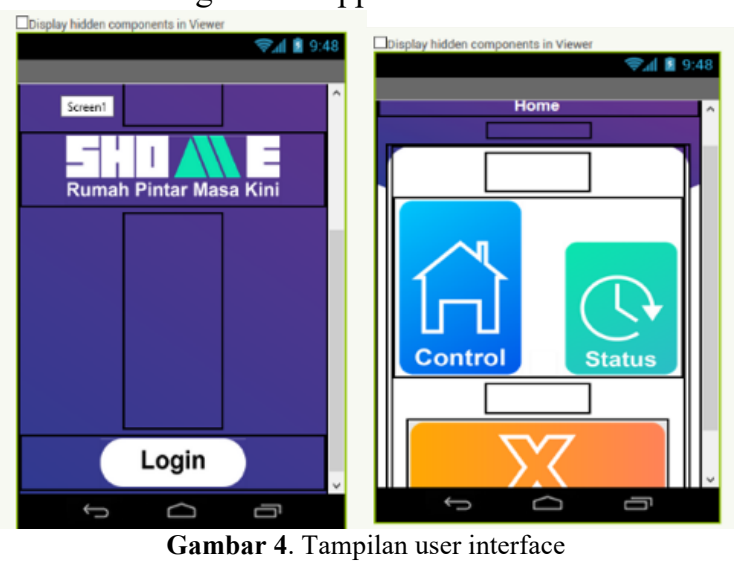

Pada gambar 4 tools yang digunakan untuk melakukan perancangan yaitu button untuk menampilkan logo berupa gambar dan button lain digunakan untuk melakukan eksekusi program menuju ke halaman login. Untuk screen login berisi pengisian email, password, tombol login, dan tombol sign up. label digunakan untuk manampilkan keterangan berupa teks, button status digunakan untuk melakukan eksekusi program menuju ke halaman control, button status digunakan untuk melakukan eksekusi program menuju ke halaman status, dan button exit digunakan untuk melakukan eksekusi program keluar dari aplikasi.

Screen kontrol digunakan untuk melakukan perancangan yaitu button yang digunakan untuk malakukan eksekusi dalam mengontrol perangkat yang terhubung, sedangkan firebaseDB digunakan penghubung menuju ke hardware untuk dilakukan eksekusi sesuai perintah.

Screen status digunakan untuk melakukan perancangan yaitu button yang digunakan untuk menampilka gambar dan label digunakan untuk menampilkan keterangan berupa teks yang dapat berupa setiap saat sesuai dengan eksekusi yang dilakukan di screen control, dimana firebaseDB digunakan sebagai penghubung dalam proses ini.

\subsection{Pengujian dengan Jaringan yang sama}

Tabel 1. Pengujian dengan jaringan yang sama

\begin{tabular}{|c|r|r|r|r|r|r|r|r|r|}
\hline \multirow{2}{*}{ Nama } & \multicolumn{7}{|c|}{ Jarak/meter } & \multirow{2}{*}{ Lokasi } \\
\cline { 2 - 8 } Perangkat & \multicolumn{2}{|c|}{2 meter } & \multicolumn{2}{|c|}{5 meter } & \multicolumn{2}{|c|}{10 meter } & \multicolumn{2}{c|}{20 meter } \\
& OFF & ON & OFF & ON & OFF & ON & OFF & ON & \multirow{2}{*}{ Hardware } \\
& ke & ke & ke & ke & ke & ke & ke & ke & \\
& ON & OFF & ON & OFF & ON & OFF & ON & OFF & \\
\hline Lampu Tamu & $\checkmark$ & $\checkmark$ & $\checkmark$ & $\checkmark$ & $\checkmark$ & $\checkmark$ & $\checkmark$ & $\checkmark$ & \\
\hline Lampu Tengah & $\checkmark$ & $\checkmark$ & $\checkmark$ & $\checkmark$ & $\checkmark$ & $\checkmark$ & $\checkmark$ & $\checkmark$ & \\
\hline Lampu Teras & $\checkmark$ & $\checkmark$ & $\checkmark$ & $\checkmark$ & $\checkmark$ & $\checkmark$ & $\checkmark$ & $\checkmark$ & \multirow{2}{*}{ Kampus 2 } \\
\hline Lampu WC & $\checkmark$ & $\checkmark$ & $\checkmark$ & $\checkmark$ & $\checkmark$ & $\checkmark$ & $\checkmark$ & $\checkmark$ & PNUP \\
\hline AC Kamar 1 & $\checkmark$ & $\checkmark$ & $\checkmark$ & $\checkmark$ & $\checkmark$ & $\checkmark$ & $\checkmark$ & $\checkmark$ & \\
\hline AC Kamar 2 & $\checkmark$ & $\checkmark$ & $\checkmark$ & $\checkmark$ & $\checkmark$ & $\checkmark$ & $\checkmark$ & $\checkmark$ & \\
\hline TV Kamar 1 & $\checkmark$ & $\checkmark$ & $\checkmark$ & $\checkmark$ & $\checkmark$ & $\checkmark$ & $\checkmark$ & $\checkmark$ & \\
\hline TV Kamar 2 & $\checkmark$ & $\checkmark$ & $\checkmark$ & $\checkmark$ & $\checkmark$ & $\checkmark$ & $\checkmark$ & $\checkmark$ & \\
\hline
\end{tabular}

Pada tabel 1 menunjukkan hasil pengujian yang dilakukan dengan jarak yang berbeda dengan menggunakan jaringan yang sama (jaringan aplikasi dan jaringan perangkat keras berada pada satu IP yang sama). Dimana pengujian ini melakukan 2 (dua) kondisi dari OFF (perangkat mati) ke ON (perangkat menyala) ataupun sebaliknya dari ON ke OFF yang menujukkan bahwa aplikasi masih dapat mengontrol hardware hingga jarak 20 meter dan pengujian ini berlokasi di Kampus 2 PNUP. 


\subsection{Pengujian dengan Jaringan yang berbeda}

Tabel 2. Pengujian dengan jaringan yang berbeda

\begin{tabular}{|c|r|r|r|r|r|r|r|r|r|}
\hline \multirow{2}{*}{ Nama } & \multicolumn{7}{|c|}{ Lokasi Aplikasi } & \multirow{2}{*}{ Loka } \\
\cline { 2 - 8 } Perangkat & \multicolumn{2}{|c|}{ BTP } & \multicolumn{2}{|c|}{ Kampu 1 PNUP } & \multicolumn{2}{|c|}{ KFC Mari } & \multicolumn{2}{|c|}{ Toraja } \\
& OFF & ON & OFF & ON ke & OFF & ON & OFF & ON & Hard \\
& ke & ke & ke & OFF & ke & ke & ke & ke & ware \\
& ON & OFF & ON & & ON & OFF & ON & OFF & \\
\hline Lampu Tamu & $\checkmark$ & $\checkmark$ & $\checkmark$ & $\checkmark$ & $\checkmark$ & $\checkmark$ & $\checkmark$ & $\checkmark$ & \\
\hline Lampu Tengah & $\checkmark$ & $\checkmark$ & $\checkmark$ & $\checkmark$ & $\checkmark$ & $\checkmark$ & $\checkmark$ & $\checkmark$ \\
\hline Lampu Teras & $\checkmark$ & $\checkmark$ & $\checkmark$ & $\checkmark$ & $\checkmark$ & $\checkmark$ & $\checkmark$ & $\checkmark$ & Kamp \\
\hline Lampu WC & $\checkmark$ & $\checkmark$ & $\checkmark$ & $\checkmark$ & $\checkmark$ & $\checkmark$ & $\checkmark$ & $\checkmark$ & us 2 \\
\hline AC Kamar 1 & $\checkmark$ & $\checkmark$ & $\checkmark$ & $\checkmark$ & $\checkmark$ & $\checkmark$ & $\checkmark$ & $\checkmark$ & PNUP \\
\hline AC Kamar 2 & $\checkmark$ & $\checkmark$ & $\checkmark$ & $\checkmark$ & $\checkmark$ & $\checkmark$ & $\checkmark$ & $\checkmark$ & \\
\hline TV Kamar 1 & $\checkmark$ & $\checkmark$ & $\checkmark$ & $\checkmark$ & $\checkmark$ & $\checkmark$ & $\checkmark$ & $\checkmark$ \\
\hline TV Kamar 2 & $\checkmark$ & $\checkmark$ & $\checkmark$ & $\checkmark$ & $\checkmark$ & $\checkmark$ & $\checkmark$ & $\checkmark$ & \\
\hline
\end{tabular}

Pada tabel 2 menunjukkan hasil pengujian Aplikasi yang dilakukan dibeberapa lokasi yang berbeda dengan menggunakan jaringan yang berbeda (jaringan aplikasi dan jaringan perangkat keras berada pada IP yang berbeda). Dimana pengujian ini melakukan 2 (dua) kondisi dari OFF (perangkat mati) ke ON (perangkat menyala) ataupun sebaliknya dari ON ke OFF yang menujukkan bahwa aplikasi masih dapat mengontrol perangkat baik itu menyalakan (ON) maupun mematikan (OFF) dengan baik di beberapa tempat seperti tabel 2 dan untuk perangkat keras (hardware) berada di lokasi Kampus 2 PNUP.

\subsection{Pengujian untuk mengetahui waktu jedah}

Tabel 3. Waktu Pengujian di Jaringan yang Sama

\begin{tabular}{|c|c|c|c|c|c|c|c|c|}
\hline \multirow{5}{*}{$\begin{array}{c}\text { Nama } \\
\text { Perangkat }\end{array}$} & \multicolumn{8}{|c|}{ Waktu Pengujian/Detik } \\
\hline & \multicolumn{2}{|c|}{2 meter } & \multicolumn{2}{|c|}{5 meter } & \multicolumn{2}{|c|}{10 meter } & \multicolumn{2}{|c|}{20 meter } \\
\hline & OFF & $\mathrm{ON}$ & OFF & $\mathrm{ON}$ & OFF & $\mathrm{ON}$ & OFF & $\mathrm{ON}$ \\
\hline & ke & ke & ke & ke & ke & ke & $\mathrm{ke}$ & ke \\
\hline & ON & OFF & ON & OFF & ON & OFF & ON & OFF \\
\hline Lampu Tamu & $24 \mathrm{~s}$ & $33 \mathrm{~s}$ & $39 \mathrm{~s}$ & $17 \mathrm{~s}$ & $5 \mathrm{~s}$ & $20 \mathrm{~s}$ & $28 \mathrm{~s}$ & $13 \mathrm{~s}$ \\
\hline Lampu Tengah & $22 \mathrm{~s}$ & $35 \mathrm{~s}$ & $26 \mathrm{~s}$ & $29 \mathrm{~s}$ & $30 \mathrm{~s}$ & $36 \mathrm{~s}$ & $30 \mathrm{~s}$ & $30 \mathrm{~s}$ \\
\hline Lampu Teras & $37 \mathrm{~s}$ & $23 \mathrm{~s}$ & $33 \mathrm{~s}$ & $37 \mathrm{~s}$ & $23 \mathrm{~s}$ & $30 \mathrm{~s}$ & $13 \mathrm{~s}$ & $39 \mathrm{~s}$ \\
\hline Lampu WC & $40 \mathrm{~s}$ & $34 \mathrm{~s}$ & $39 \mathrm{~s}$ & $32 \mathrm{~s}$ & $18 \mathrm{~s}$ & $23 \mathrm{~s}$ & $27 \mathrm{~s}$ & $23 \mathrm{~s}$ \\
\hline AC Kamar 1 & $21 \mathrm{~s}$ & $35 \mathrm{~s}$ & $34 \mathrm{~s}$ & $32 \mathrm{~s}$ & $16 \mathrm{~s}$ & $21 \mathrm{~s}$ & $32 \mathrm{~s}$ & $34 \mathrm{~s}$ \\
\hline AC Kamar 2 & $34 \mathrm{~s}$ & $21 \mathrm{~s}$ & $36 \mathrm{~s}$ & $25 \mathrm{~s}$ & $22 \mathrm{~s}$ & $35 \mathrm{~s}$ & $30 \mathrm{~s}$ & $22 \mathrm{~s}$ \\
\hline TV Kamar 1 & $31 \mathrm{~s}$ & $30 \mathrm{~s}$ & $31 \mathrm{~s}$ & $33 \mathrm{~s}$ & $30 \mathrm{~s}$ & $19 \mathrm{~s}$ & $22 \mathrm{~s}$ & $32 \mathrm{~s}$ \\
\hline TV Kamar 2 & $25 \mathrm{~s}$ & $35 \mathrm{~s}$ & $35 \mathrm{~s}$ & $21 \mathrm{~s}$ & $10 \mathrm{~s}$ & $29 \mathrm{~s}$ & $26 \mathrm{~s}$ & $24 \mathrm{~s}$ \\
\hline
\end{tabular}

Pada tabel 3 merupakan pengujian waktu jeda pada perangkat elektronik hingga menyala $(\mathrm{ON})$ ataupun mati (OFF) di beberapa jarak yang berbeda dengan menggunakan jaringan yang sama (jaringan aplikasi dan jaringan hardware berada pada IP yang sama). Seperti yang dilihat diatas waktu terlama perangkat merespon yaitu $40 \mathrm{~s}$ dan waktu paling cepat perangkat merespon ${ }^{\text {[3 }}$ yaitu 5 s. Sehingga dapat disimpulkan bahwa respon perangkat terhadap aplikasi membutuhkan waktu jeda sekita 5 detik - 40 detik, ini terjadi karena adanya pengulangan status yang terjadi didalam program perangkat keras (hardware).

Tabel 4. Waktu Pengujian di Jaringan yang Berbeda

\begin{tabular}{|c|c|c|c|c|c|c|c|c|}
\hline \multirow{2}{*}{$\begin{array}{c}\text { Nama } \\
\text { Perangkat }\end{array}$} & \multicolumn{6}{|c|}{ Waktu Pengujian/Detik } \\
\cline { 2 - 9 } & \multicolumn{2}{|c|}{ BTP } & \multicolumn{2}{|c|}{ Kampus 1 PNUP } & \multicolumn{2}{|c|}{ KFC Mari } & \multicolumn{2}{|c|}{ Toraja } \\
\cline { 2 - 9 } & ON & OFF & ON & OFF & ON & OFF & ON & OFF \\
\hline Lampu Tamu & $13 \mathrm{~s}$ & $20 \mathrm{~s}$ & $31 \mathrm{~s}$ & $32 \mathrm{~s}$ & $14 \mathrm{~s}$ & $9 \mathrm{~s}$ & $14 \mathrm{~s}$ & $30 \mathrm{~s}$ \\
\hline Lampu Tengah & $23 \mathrm{~s}$ & $33 \mathrm{~s}$ & $5 \mathrm{~s}$ & $21 \mathrm{~s}$ & $15 \mathrm{~s}$ & $31 \mathrm{~s}$ & $20 \mathrm{~s}$ & $35 \mathrm{~s}$ \\
\hline Lampu Teras & $23 \mathrm{~s}$ & $34 \mathrm{~s}$ & $17 \mathrm{~s}$ & $34 \mathrm{~s}$ & $19 \mathrm{~s}$ & $15 \mathrm{~s}$ & $34 \mathrm{~s}$ & $34 \mathrm{~s}$ \\
\hline Lampu WC & $31 \mathrm{~s}$ & $33 \mathrm{~s}$ & $32 \mathrm{~s}$ & $36 \mathrm{~s}$ & $29 \mathrm{~s}$ & $33 \mathrm{~s}$ & $34 \mathrm{~s}$ & $37 \mathrm{~s}$ \\
\hline AC Kamar 1 & $30 \mathrm{~s}$ & $33 \mathrm{~s}$ & $32 \mathrm{~s}$ & $33 \mathrm{~s}$ & $7 \mathrm{~s}$ & $18 \mathrm{~s}$ & $33 \mathrm{~s}$ & $33 \mathrm{~s}$ \\
\hline AC Kamar 2 & $33 \mathrm{~s}$ & $37 \mathrm{~s}$ & $32 \mathrm{~s}$ & $35 \mathrm{~s}$ & $17 \mathrm{~s}$ & $36 \mathrm{~s}$ & $34 \mathrm{~s}$ & $35 \mathrm{~s}$ \\
\hline TV Kamar 1 & $30 \mathrm{~s}$ & $34 \mathrm{~s}$ & $25 \mathrm{~s}$ & $33 \mathrm{~s}$ & $20 \mathrm{~s}$ & $23 \mathrm{~s}$ & $30 \mathrm{~s}$ & $36 \mathrm{~s}$ \\
\hline TV Kamar 2 & $30 \mathrm{~s}$ & $32 \mathrm{~s}$ & $32 \mathrm{~s}$ & $35 \mathrm{~s}$ & $27 \mathrm{~s}$ & $21 \mathrm{~s}$ & $33 \mathrm{~s}$ & $35 \mathrm{~s}$ \\
\hline
\end{tabular}

Pada tabel 4 merupakan pengujian waktu jeda pada perangkat elektronik hingga menyala $(\mathrm{ON})$ ataupun mati (OFF) di beberapa lokasi yang berbeda dengan menggunakan jarinag yang berbeda (jaringan aplikasi dan jaringan hardware memiliki IP yang berbeda). Seperti yang dilihat diatas waktu terlama perangkat merespon yaitu $37 \mathrm{~s}$ dan waktu paling cepat perangkat merespon yaitu $5 \mathrm{~s}$. Sehingga dapat disimpulkan bahwa respon perangkat terhadap aplikasi membutuhkan waktu jeda sekita 5 detik - 37 detik, ini terjadi karena adanya pengulangan status yang terjadi didalam program perangkat keras (hardware) dan aplikasi dapat digunakan dimana saja.

\section{Kesimpulan}

Dari hasil penelitian ini dapat disimpulkan bahwa pada aplikasi ini dapat dilakukan pengontrolan dengan jarak 20 meter dengan menggunakan jaringan yang sama (aplikasi dan hardware menggunakan IP yang sama) dan Pengontrol aplikasi dengan hardware memiliki waktu jedah 5-40 detik dengan menggunakan jaringan yang sama. Pengontrolan aplikasi dengan hardware memiliki waktu jedah 5-37 detik denggan menggunakan jaringan yang berbeda ( jaringan apilkasi dan jaringan hardware memiliki IP yang berbeda). Pengontrolan aplikasi dengan hardware memiliki waktu jedah $5-37$ detik denggan menggunakan jaringan yang berbeda ( jaringan apilkasi dan jaringan hardware memiliki IP yang berbeda).

\section{Daftar Rujukan}

1] Rachman, Dhenny dkk. 2017. Sistem Pemantau \& Pengendalian Rumah Cerdas Menggunakan Infrastuktur Internet Messaging. Jurnal Link vol. 26/ no. 1/ Februari 2017. ISSN 1858-4667

[2] Putra, Leo Putra, dan Arif Rahman Hakim. Sistem Kendali Lampu Cerdas Pada Smarthome Berbasis Android mengunakan Metode Fuzzy Logic Control. Computer Science Research and its Development Journal (CSRID). 10.22303/csrid.10.1.2018.9-19. 2018

Mahali, Muhammad Izzuddin. 2016. Smart Door Locks Based On Internet Of Things Concept With Mobile Backend as a services. 
Jurnal electronics, informatics, and vocational education (ELINVO), volume 1, nomer 3, Nopember 2016

[4] Dewi, Andriana Kusuma dkk. 2017. Sistem Kendali Buka Tutup [7] Atap Rumah Untuk Smarthome Dengan Menggunakan Android Smartphone, Jurnal Teknologi dan sistem Komputer, 5(1), 2017, 43-48, Doi: 10.14710/ttsiskom.5.1.2017.43-48

[5] Rochman, Hudan Abdur dkk. 2017. Sistem Kendali Berbasis Mikrokontroler Menggunakan Protokol MQTT pada Smarthome. Jurnal Pengembangan Teknologi Informasi dan Ilmu Komputer (JPTIIK), vol 1 no. 6, 2017

[6] Masykur, Fauzan, dan Figiana Prasetiyowati. 2016. Aplikasi Rumah Pintar (Smart Home) Pengendali Peralatan Elektronik Rumah Tangga Berbasis Web. Jurnal Teknologi Informasi dan
Ilmu Komputer. Vol. 3, no.1. p-ISSN: 2355-7699, e-ISSN: 2528 6579.

Paul, Chinju et. al. 2018. An Overview of IoT based smart homes. International Conference on Inventive Systems and Control (ICISC). 2018

[8] Parthornratt, Tussanai el.al. 2018. A Smart Home Automation via Facebook Chatbot and Raspberry Pi. International Conference on Engineering Innovation (ICEI). 2018 